\title{
A pesquisa em Ensino de Botânica: contribuições e características da produção científica em periódicos
}

\section{The research on Botany Teaching: analysis of the contributions and characteristics of scientific production in journals}

\author{
Lucas Dias Leopoldo (diasleopoldo@gmail.com) \\ Programa de Pós-Graduação em Educação para a Ciência \\ Universidade Estadual "Júlio de Mesquita Filho" (UNESP) - Câmpus Bauru \\ Fernando Bastos (f.bastos@unesp.br) \\ Programa de Pós-Graduação em Educação para a Ciência \\ Universidade Estadual "Júlio de Mesquita Filho" (UNESP) - Câmpus Bauru
}

\begin{abstract}
Resumo:
Esta pesquisa teve como objetivo apresentar os resultados e contribuições de publicações sobre o Ensino de Botânica, relacionadas ao âmbito de um setor de produção e divulgação científica. A metodologia consistiu na escolha de quatro periódicos de referência pertencentes à área de Ensino de Ciências, na realização de levantamentos em edições compreendidas entre os anos de 2010 a 2016, e discussões envolvendo os resultados e contribuições obtidos. Os aspectos encontrados refletiram uma produção incipiente de artigos que realizassem uma interlocução entre o Ensino de Botânica e a pesquisa em Ensino de Ciências. Tal cenário implica a necessidade de maiores estudos sobre a produção de conhecimentos para a área, a fim de se identificar lacunas em outros setores de produção e promover uma maior divulgação do Ensino de Botânica.
\end{abstract}

Palavras-chave: Ensino de Botânica; Biologia; Ensino de Ciências.

\begin{abstract}
:
The research aims to present the results and contributions of publications on Botany Teaching, related to the scope of a sector of production and dissemination of science. The methodology applied consisted of the selecting of four reference journals belonging to the area of Science Teaching, in which we conducted surveys in editions between the years 2010 to 2016, and later discussed the results and contributions obtained. The texts found reflected an incipient production of articles that carried out a dialogic articulation between Botany Teaching and the research in Science Teaching. Such scenario implies the need for further studies on the production of knowledge for the area, in order to identify gaps in other production sectors and to promote greater dissemination of Botany Education.
\end{abstract}

Keywords: Botany Teaching; Biology; Science Education. 


\section{INTRODUÇÃO}

A Botânica é um campo da Biologia de grande importância, por meio do seu estudo são produzidos vários componentes que promovem a qualidade de vida e a sobrevivência humana. Apesar dessa relevância, seu ensino tem sido negligenciado em virtude de abordagens pautadas pela memorização de terminologias, pouca contextualização histórica, cargas horárias escolares insuficientes, falta de diversificação metodológica e outros fatores (SILVA; CAVALLET; ALQUINI, 2006, LEME; URSI, 2014).

Reverter este quadro problemático implica a mobilização de esforços por pesquisadores de modo a apontar alternativas e soluções. Tais iniciativas estão relacionadas a âmbitos escolares, acadêmicos e de espaços não formais, onde são desenvolvidas atividades como as visitações e experiências com plantas (SILVA; GHILARDI-LOPES, 2014, SCHNEEKLOTH, 1989, TUNNICLIFFE; REISS, 2000), e processos de Formação Inicial com a análise das concepções de futuros professores sobre a Botânica (TOWATA; URSI; SANTOS 2010, SILVA; SANO, 2011).

Os resultados dessas pesquisas são veiculados por meio de artigos, e a circulação desses produtos se dá por meio de periódicos especializados que permitem um enfoque de produção para áreas específicas como a Botânica, Genética, Zoologia, dentre outras pertencentes ao campo do Ensino de Ciências.

O referido campo de conhecimento trata de questões interligadas com as áreas da Educação e Ciências Naturais, tendo se desenvolvido desde o início da década de 1970, e agregado ao longo de quase cinco décadas várias teses, dissertações e demais produções. De acordo com o aumento das pesquisas e dispersão dos focos de investigação para diferentes temáticas, as contribuições, tendências ou problemas no Ensino de Ciências foram se tornando difíceis de identificar (FERNANDES; MEGID, 2007).

A partir desse contexto, conhecer o conteúdo dos trabalhos produzidos, por meio de análises das publicações veiculadas, possibilita a identificação de lacunas, de novas interlocuções entre ciência e educação, além de demandas para um determinado tema (RAZERA, 2016). Tal estilo de pesquisa se assemelha aos objetivos do presente artigo, 
em que se pretende identificar algumas características da produção científica sobre o Ensino de Botânica.

Por meio desse norteamento, investigamos quatro periódicos vinculados à área de Ensino de Ciências descrevendo as contribuições e características do Ensino de Botânica: Ciência \& Educação, Revista Brasileira de Pesquisa em Educação em Ciências (RBPEC), Investigações em Ensino de Ciências (IENCI) e Ensaio Pesquisa em Educação em Ciências.

\section{METODOLOGIA}

Trata-se de uma pesquisa qualitativa de cunho documental. Para a elaboração dos levantamentos sobre a pesquisa em Ensino de Botânica, foi consultado um núcleo de produção científica, ou setor, entendido como meio de divulgação representativo. O âmbito de análise correspondeu então aos quatro periódicos voltados para o Ensino de Ciências melhor avaliados de acordo com os procedimentos Qualis, desenvolvidos pela Coordenação de Aperfeiçoamento do Pessoal de Nível Superior (Capes) no último quadriênio (2013-2016).

O setor de produção escolhido possui endereços eletrônicos na internet com os catálogos e trabalhos disponíveis para acesso. Para cada triagem, foram aplicados quatro descritores constituídos pelos radicais de palavras relativas à Botânica: "veg", "bot", "plant" e "fotoss", dessa maneira durante a busca foi possível captar qualquer termo, fosse ele uma palavra-chave, parte do título ou de texto cujo sufixo, prefixo, pluralidade ou tempo verbal gerasse uma palavra derivada como "botânico", "botânicas", "botany", "fotossintético", "fotossintetizante", "plantae", "plantando", "vegetação", "vegetais", dentre outros.

Alguns artigos continham os descritores utilizados na busca, mas envolviam objetos de pesquisa voltados para os estudos da Ecologia, Zoologia, dentre outros, com breves menções às plantas. Por não tratarem especificamente do Ensino de Botânica, os levantamentos foram além da identificação por palavras, implicando a leitura dos textos para a identificação das suas temáticas centrais. 
A natureza deste trabalho difere de uma abordagem do tipo "estado da arte", permanecendo focado no âmbito da produção científica em Educação para o Ensino de Botânica. Trata-se de uma metapesquisa que pode subsidiar estudos de maior amplitude, aproximando-se do que Romanowski e Ens (2006) definiram como uma abordagem do "estado de conhecimento" de uma área. Essa diferença se dá em virtude da análise delimitar-se a um setor de produção, que, no caso do presente artigo, são os periódicos vinculados ao Ensino de Ciências.

\section{RESULTADOS E DISCUSSÕES}

A análise compreendeu o conjunto de artigos publicados entre os anos de 2010 a 2016 nas revistas Ciência \& Educação, Revista Brasileira de Pesquisa em Educação em Ciências (RBPEC), Investigações em Ensino de Ciências (IENCI) e Ensaio:

Quadro 1 - Periódicos levantados, total de artigos publicados entre 2010 e 2016 e artigos relacionados ao Ensino de Botânica.

Fonte - Adaptado da dissertação "Proposições para reflexão sobre a Formação Continuada de professores em Ensino de Botânica” (LEOPOLDO; 2018).

\begin{tabular}{|c|c|c|}
\hline Revistas & $\begin{array}{c}\text { Artigos publicados } \\
\text { entre 2010 e 2016 }\end{array}$ & $\begin{array}{c}\text { Artigos relacionados } \\
\text { ao Ensino de Botânica }\end{array}$ \\
\hline $\begin{array}{c}\text { Ciência \& } \\
\text { Educação }\end{array}$ & 405 & - \\
\hline RBPEC & 223 & 1 \\
\hline IENCI & 217 & 4 \\
\hline Ensaio & 211 & 2 \\
\hline Total & 1056 & 7 \\
\hline
\end{tabular}

Pela observação do Quadro 1, é possível notar que a revista IENCI sozinha possui mais publicações do que todos os outros periódicos juntos. Esse cenário aponta uma quantidade baixa de publicações relacionadas ao Ensino de Botânica; e, além disso, revela uma distribuição e cobertura desigual entre as revistas sobre o tema.

A análise em sequência dos periódicos se iniciará pelo que forneceu a maior quantidade de material relacionado ao Ensino de Botânica, a revista IENCI, com quatro 
artigos. Para tornar mais visível e fácil a leitura, cada título correspondente ao seu respectivo artigo foi enumerado como uma subseção.

\section{1- A ação mediada no processo de formação dos conceitos científicos de fotossíntese e respiração celular em aulas de biologia.}

As autoras Trazzi e Oliveira (2016a) realizam por meio desse trabalho a análise de interações discursivas entre uma professora e seus estudantes do $1^{\circ}$ ano do Ensino Médio, ocorridas durante dois experimentos em sala de aula. As temáticas estudadas foram a Fotossíntese e a Respiração Celular.

O tempo do experimento foi de duas semanas com a observação de duas plantas, uma em ambiente fechado, com iluminação e terra, a outra em ambiente aberto sob as mesmas condições. Em função do experimento, a professora promoveu discussões sobre a relação do gás carbônico, água, glicose e oxigênio, tentando indicar que nos processos de Fotossíntese e Respiração Celular os elementos químicos envolvidos, apesar de semelhantes, poderiam possuir finalidades diferentes.

As autoras enfocaram as estratégias de ensino que a professora participante adotou para ensinar os conteúdos. Nesse sentido identificaram detalhadamente as situações que a docente formulou, dando ênfase a passagens em que foi utilizada uma estratégia de conflito de ideias, como o fato de os animais respirarem por estruturas que os vegetais não têm, como boca, nariz e pulmão, ou uma planta sobreviver em um ambiente fechado contrapondo-se à ideia comum entre os alunos de que o vegetal morreria.

Além das descrições centradas nas ações da professora, a utilização do experimento como opção didática com as duas plantas foi um fator positivo, pois a planta que supostamente teria mais chances de sobreviver, por estar em um ambiente aberto, morreu. $\mathrm{O}$ que poderia ser entendido como uma falha foi aproveitado pela professora para exemplificar, de acordo com o que aponta Gil Pérez et al. (2001), que a ciência não é um processo infalível de descobertas, mas um percurso que comporta incertezas.

Outro fator que se destaca é a gama de conceitos principais difíceis de serem trabalhados em Botânica, mesmo com apontamentos no quadro negro e auxílio da 
professora, as relações entre Fotossíntese e Respiração Celular não puderam ser demonstradas de maneira visível e foram acompanhadas de muitos termos agregados. $\mathrm{O}$ nível de complexidade em si representa uma dificuldade nesse contexto da aula expositiva, e mesmo em outros meios de apresentação do conteúdo, como o livro didático, entendidos como fontes seguras, o desafio de simplificar os conceitos é grande.

Os autores alcançaram o objetivo do artigo trilhando uma perspectiva predominantemente descritiva. Nesse sentido as contribuições para o leitor se deram por meio de exemplos de mediações que o professor pôde realizar com os alunos em aulas de Botânica, incluindo nessa descrição os fatores inesperados ou de interação que surgiram durante as atividades. Embora trate apenas de dois conceitos (Respiração Celular e Fotossíntese), as interações nos momentos de ensino transcritos no trabalho analisado demonstram a possibilidade de um diálogo fluído e estimulante entre professor e aluno.

\section{2 - Significados de Fotossíntese apropriados por alunos do Ensino} Fundamental a partir de uma atividade investigativa mediada por multimodos de representação.

O objetivo desse trabalho consistiu em saber quais significados sobre a Fotossíntese estudantes do sexto ano do Ensino Fundamental criam quando ensinados por diferentes tipos de representações, como textos, figuras e desenhos.

Os autores Zompero e Laburu (2011) utilizaram a teoria da aprendizagem significativa, classificando, em quadros, os significados produzidos. Um experimento foi realizado colocando-se uma planta em ambiente aberto, e outra em ambiente fechado, e diferentemente do experimento do artigo anterior (3.1), o ambiente foi fechado com um plástico privando o vegetal de luz.

Foram desenvolvidas três intervenções em que o referido experimento figurou como o foco de discussões, dos levantamentos de hipóteses e da criação de textos por meio de uma figura e um desenho. Os estudantes demonstraram várias concepções ao longo das atividades como a noção de o capim ser vivo por ser verde, e uso da palavra "hipótese" como sinônimo de "suposição". 
Em outro momento, os autores puderam identificar nos discursos transcritos relações de coerência entre os efeitos da luminosidade e ocorrência da Fotossíntese, aliadas à noção da importância de ambas para a vida na Terra; também notaram relações cientificamente incoerentes, como o fluxo da glicose no vegetal ter como destino o solo e a planta ser incapaz de realizar Fotossíntese na ausência de luz.

Com base nessas percepções os autores mencionaram a importância de estudos sobre a dificuldade do entendimento da Fotossíntese e a Respiração, e se depararam, ao longo da pesquisa, com a menção equivocada do conceito de respiração por estudantes. Em vista dessa presença na fala dos estudantes, uma discussão maior sobre o conceito de Respiração Celular poderia ter sido desenvolvida no estudo, pois em muitos momentos a menção dos gases carbônico e oxigênio atraiu as significações dos alunos para o sentido comum da palavra respiração, mas o estudo não explorou esse fato, desenvolvendo-se exclusivamente voltado para o conceito de Fotossíntese.

Ao não aprofundar as implicações de significação do conceito Respiração Celular, foram perdidas no artigo oportunidades de uma discussão mais completa com relação ao referencial da teoria da aprendizagem significativa sobre o processo fotossintético.

Além dos equívocos entre Fotossíntese e Respiração, os participantes entraram em contato com o tema de maneira mais específica pela primeira vez, o que intensificou a dificuldade de entendimento dos conceitos e as relações entre os fenômenos químicos e biológicos, podendo este ter sido um fator influente na característica dos dados coletados. Apesar desses obstáculos os autores trazem ao leitor a conclusão de que há uma incorporação de palavras novas pelos alunos em seus vocabulários cotidianos como clorofila e ocorre uma maior familiaridade com outros conceitos relativos à Fotossíntese.

A última crítica a se realizar consistiu no fato de o artigo não discutir e destacar quais as relações entre as experiências sociais dos estudantes envolvidos nas intervenções com as suas concepções prévias de modo mais específico. Estes aspectos possuem um papel essencial, pois as séries iniciais do Ensino Fundamental representam para a criança um momento novo, de contato recente entre os conhecimentos cotidianos e científicos relacionados à Botânica. 
Estudos em outros países como os de Gatt et al. (2007), Simmons (1994) e Tunnicliffe e Reiss (2000) envolvendo crianças entre o quinto e o sétimo ano, constataram que muitos significados no tocante às plantas fazem parte dos valores e conhecimentos aprendidos no cotidiano doméstico e familiar, ou seja, âmbitos que no contexto dos estudantes que participaram do estudo, poderiam ter fornecido informações mais próximas das influências da realidade brasileira sobre o aprendizado de Botânica.

Sob uma perspectiva ampla para o campo do Ensino de Botânica o artigo analisado aponta que a curta experiência de vida das crianças nos anos iniciais em ambientes formais como a escola, frente a uma maior vivência social e cultural em espaços informais, implica em uma maior incorporação conceitual com base na associação dos conceitos científicos ao significado comum e literal das palavras, sendo maior o esforço para vincular os significados cientificamente aceitos de Respiração Celular, oxigênio e gás carbônico com a produção de energia na planta ou um processo como a Fotossíntese.

\section{3 - Botânica geral de Angiospermas no Ensino Médio: uma análise comparativa entre livros didáticos.}

Para este trabalho, três livros didáticos correspondentes aos anos de 1974, 1999 e 2011 tiveram os seus conteúdos relativos ao grupo vegetal das Angiospermas analisados. Como introdução, os autores Marinho, Setúval e Azevedo (2015) resgataram um histórico sobre o currículo de Ciências e como o livro didático se insere nesse contexto.

No artigo discute-se que os livros didáticos, ao longo das décadas, tendem a incorporar uma linguagem mais técnica sobre os conteúdos de Angiospermas. Dessa maneira, os conceitos são apresentados e logo definidos de maneira mais direta, sem uma contextualização, descrição ou problematização mais aprofundadas.

Essa compactação do conteúdo tem relação com diversos fatores. No caso do livro publicado em 1974, o estudante dessa época do Ensino Médio não havia cursado disciplinas de Ciências no Ensino Fundamental, pois estas ainda não estavam estabelecidas e aplicadas no sistema educacional. Em função dessa lacuna, foi distribuído um livro didático com descrições abrangentes, sem muitos termos 
específicos em Botânica. Na edição analisada do ano de 1999, a linguagem seguiu um estilo mais técnico, com a apresentação de conceitos sobre Angiospermas e logo em seguida sua definição, sem relacioná-los com o contexto evolutivo ou ecológico.

A edição mais recente (2011) foi onde se identificou uma superação maior da fragmentação dos conteúdos sobre Angiospermas. Dentre os aspectos positivos, foram destacados: a interlocução dos conceitos de Botânica com outros conteúdos da área da Biologia, a promoção de uma relação entre os conceitos científicos e cotidianos do estudante por meio de quadros conceituais, e a facilitação do entendimento do conteúdo por meio de imagens e esquemas explicativos.

Mesmo com esses avanços tornando a aprendizagem mais interessante, os autores ressaltaram que é importante o professor selecionar o livro "adequado aos seus alunos e à proposta pedagógica da escola". Esse cuidado, levando em consideração as ideias de Güllich e Silva (2013), deve-se ao fato de o livro didático interferir na articulação e no ensino de Ciências, orientando o trabalho docente e algumas vezes extrapolando seu papel de instrumento didático.

Os autores do artigo dessa subseção concluíram que o livro didático de 2011 apresentou um sinal positivo ao distanciar o conteúdo de Botânica de um caráter puramente descritivo, marcado pela memorização de terminologias e falta de conexão com a realidade do aluno. Um dos fatores de contribuição para essa melhora provavelmente foi o rigor na avaliação promovida pelo Programa Nacional do Livro Didático (PNLD) e o seu aprimoramento.

Mesmo com os avanços no padrão de qualidade do livro didático, Güllich e Silva (2013) pontuam que ainda são poucos os estudos sobre os discursos presentes nas políticas públicas educacionais, existindo dificuldades na aproximação entre as ideias produzidas nesses âmbitos e os processos de formação de professores.

Esses tipos de pesquisa envolvendo políticas públicas são de grande relevância pois, de acordo com Apple (2014), as relações de acúmulo de poder político e econômico desiguais na sociedade; geram tensões e definem características para os currículos em educação. Desse modo, pesquisas sobre o livro didático como a publicada no artigo colaboram também para o fomento de posicionamentos críticos sobre os 
currículos elaborados, na percepção das tendências de ensino ao longo do tempo e no aprimoramento do conteúdo organizado para os estudantes.

\section{4 - Caracterização ontológica do conceito de Fotossíntese e obstáculos} epistemológicos e ontológicos relacionados com o Ensino deste conceito.

A seguinte pesquisa orienta-se pela mobilização de conceitos do campo da Filosofia e Educação por Dimov, Pechliye e Jesus (2014). Para cumprir os objetivos de propor uma categoria ontológica sobre o conceito de Fotossíntese, e identificar obstáculos desse domínio e do âmbito epistemológico, os autores trabalharam com cinco estudantes do primeiro ano do Ensino Médio.

Primeiramente, foram definidas as propriedades ontológicas do fenômeno da Fotossíntese como um processo de caráter aleatório, sem um propósito, sem uma meta definida, composto por acontecimentos simultâneos, dentre outros aspectos.

Em seguida, identificaram no discurso dos estudantes um distanciamento com essas propriedades por meio da frase "A Fotossíntese é o processo que limpa e renova o ar”. Essa colocação supõe, segundo os autores, uma origem do fenômeno justificada por um propósito, incorrendo em uma afirmação de natureza teleológica distanciada dos parâmetros ontológicos estipulados para a Fotossíntese. Outras manifestações de cunho teleológico foram encontradas quando os alunos reconhecem que o oxigênio produzido no processo da Fotossíntese "não é simplesmente para jogar no ar".

O último passo dos objetivos do artigo em questão foi a identificação de obstáculos epistemológicos com base nas definições de Bachelard (2007). Alguns deles foram identificados pelos autores, como o obstáculo "pragmático" que esteve presente na noção dos estudantes de que o oxigênio proveniente da Fotossíntese; é produzido de maneira utilitária e propositada para a respiração do homem ou da própria planta, e o obstáculo epistemológico chamado de "obstáculo da experiência primeira", que ocorreu quando um estudante ao observar pela primeira vez folhas com aparência acinzentada na rua, considerou de maneira ingênua a planta como um filtro, em que detritos permanecem na superfície da folha deixando o ar mais limpo.

Os objetivos com relação aos âmbitos ontológicos e epistemológicos foram atingidos no artigo mas houve uma lacuna com relação à aprendizagem e diálogo com o conceito de Respiração, sendo que o termo participa do discurso dos estudantes em 
diferentes momentos, a exemplo do que ocorre no artigo analisado no ponto 3.2 de Zompero e Laburu (2011).

Dentre algumas das conclusões do artigo de Dimov, Pechliye e Jesus, temos, nos diálogos com os estudantes, esclarecimentos e discussões sobre concepções teleológicas, como a noção de que as plantas também produzem o oxigênio com a finalidade de utilizá-lo na respiração. Esse é um ponto positivo que contribui para a educação científica com relação ao conceito Botânico da Fotossíntese. Mayr (2004) aponta que a teleologia deve ser evitada no contexto do pensamento biológico pois induz ao erro, a incoerências sobre o pensamento científico, além de abrir espaço para concepções em Biologia relativas a forças sobrenaturais ou entendimentos Lamarquistas sobre processos naturais como a Evolução.

Outra contribuição está na caracterização da Fotossíntese em sua ontologia e na identificação de contradições epistemológicas presentes em uma disciplina do Ensino de Botânica, obstáculos esses que, segundo Bachelard (2007), geram "estagnação e até regressão", sobrepondo concepções equivocadas sobre as cientificamente coerentes e incorrendo a pessoa a cometer mais erros.

A análise acima encerra o conjunto de subseções envolvendo a revista Investigações em Ensino de Ciências. Seguem abaixo as contribuições do artigo publicado pela Revista Brasileira de Pesquisa em Educação em Ciências (RBPEC):

\section{5 - I Always Enjoyed Touching the Soil and Growing Things!}

Esta investigação foi realizada por Rahm (2014) nas dependências de um jardim botânico localizado em Montreal, os resultados foram alcançados pela análise de entrevistas semiestruturadas com 14 estudantes de 12 a 14 anos. Esses jovens participaram de um projeto chamado "The Youth Garden", em que hortas foram cultivadas em sessões de plantação, colheita e uma confraternização final.

Durante o projeto, emergiram interações e percepções em que os participantes se ajudaram no manuseio de ferramentas como tesouras de poda e realizaram interfaces das atividades com outros âmbitos, como fez uma garota ao comentar que gostou de cultivar vegetais em uma horta do projeto, pois os legumes colhidos não teriam um custo agregado, ajudando a economizar dinheiro para sua família, além de serem saudáveis em função de sua qualidade orgânica. 
A autora enfatizou a importância do caráter comunitário, do ambiente propício de interação social, da promoção da Educação Ambiental, a interação e percepção das características dos vegetais, a inclusão da comunidade circundante, dentre outros fatores.

Por meio desses apontamentos e trechos do artigo, Rahm (2014) revela que o uso de espaços não formais possui um grande potencial para o surgimento de situações de aprendizagem que costumam ocorrer durante as aulas de Botânica em sala. Nas passagens transcritas pela autora, temos um jovem comentando que as folhas da planta que cultiva crescem mais quando recebem uma quantidade maior de luminosidade, e que aprendeu isso nas aulas de Biologia. Mesmo que essa informação seja uma concepção simplificada, o adolescente conectou a sua experiência escolar com a atividade em campo, indicando que este espaço consiste em um local propício para o esclarecimento de questões científicas e até concepções alternativas.

Essa aproximação fornece indícios de que há possibilidades de um intercâmbio promissor de aprendizagens entre o meio escolar e o não formal. Tal viabilidade indica maneiras de superar o desinteresse e a negligência sobre o Ensino de Botânica, atraindo a atenção tanto de estudantes como de professores.

A diversificação de metodologias, modificando a rotina dos alunos, já seria um primeiro passo na melhoria das abordagens em Botânica na escola, mas, para tanto, fazse necessário escolher um local adequado para promover experiências de ensino e aprendizagem. Nesse contexto, Dias, Schwarz e Vieira (2000) também utilizaram o espaço do Jardim Botânico, mas de forma mais específica do que Rahm (2014), pois ministraram aulas de Botânica. Tal experiência revelou o espaço não formal do jardim botânico como um espaço dinâmico e estimulante, em que os estudantes participaram coletivamente de atividades, entraram em contato com as plantas e trabalharam questões interdisciplinares como os aspectos de Educação Ambiental em conservação da biodiversidade.

Glória Gohn (2006) traz uma discussão sobre os resultados esperados para além dos vinculados à educação formal nos processos de aprendizagem em espaços não formais. São produtos ligados à cidadania, ética e direitos humanos, como a produção 
de interações coletivas, o fomento de luta por justiça social ou uma causa política, a interpretação do mundo pela prática, e a promoção da autovalorização ou autoestima.

Rahm (2014) presenciou os aspectos trazidos por Gohn, de resultados mais ligados ao âmbito social e político do que propriamente ao ensino específico sobre uma disciplina escolar. Os participantes falaram durante as entrevistas que houve redução do estresse ao se trabalhar na prática com a Botânica nas hortas e interagir em grupo de maneira comunitária, dentre outros aspectos positivos.

Cabe ressaltar que a experiência no jardim botânico teve um papel atrelado à uma racionalidade crítica que também foi levado em consideração por Rahm. Essa perspectiva foi defendida pela autora ao comentar a importância do projeto "The Youth Garden", tanto no incentivo do combate à marginalização da educação ambiental, quanto no fortalecimento de uma atitude mais ativista em ciências e acessibilidade da população a essas pautas.

O último periódico que conteve trabalhos relacionados ao Ensino de Botânica foi a revista Ensaio Pesquisa em Educação em Ciências, totalizando 2 artigos, discutidos abaixo nos pontos $\mathbf{3 . 6}$ e 3.7:

\section{6 - Possibilidades de Ensino de Botânica em um espaço não formal de educação na percepção de professoras de ciências.}

Esta investigação aproximou o contexto específico dos conteúdos de ensino a um processo de Formação Continuada, em que possíveis usos de um espaço não formal foi discutido em função do Ensino de Botânica. As atividades envolveram grupos de professores que responderam dois questionários e participaram de uma atividade chamada "Chá de Sentidos", nos canteiros de plantas aromáticos dispostos em um museu.

Os professores responderam o primeiro questionário sobre o entendimento do que são espaços formais e não formais desenvolvido pelos autores da pesquisa, Faria, Jacobucci e Oliveira (2011). Nessa etapa, os docentes de Ciências demonstraram dificuldades em classificar espaços formais e não formais dentro da escola, apontando significados abrangentes como "Um lugar onde existam mais regras", mas entenderam 
que a realização de atividades fora do ambiente escolar, apesar de ser trabalhoso, é uma possibilidade de tornar o ensino mais prático, descontraído e importante.

Posteriormente, participaram da experiência "Chá de Sentidos" em que precisariam sentir o odor, o gosto, e observar algumas ervas aromáticas. Alguns deles se confundiram, associando características semelhantes a espécies diferentes, como sentir o gosto de orégano e depois pelo aroma descobrir ser poejo, ou conseguir diferenciar a folha de erva cidreira e hortelã pelo tato, mas não pela visão.

Os fatos mencionados acima vieram acompanhados de falas que evidenciaram alguns componentes da "cegueira botânica" (SALATINO; BUCKERIDGE, 2016), como o comentário de um dos professores sobre apenas conhecer algumas das plantas por seu nome estampado em saquinhos de supermercado, e outro docente que confundiu os nomes das plantas, mas mencionou que sempre "via" na casa de sua mãe as mesmas espécies.

Os autores, concluíram por meio das associações realizadas pelos professores durante o experimento, entre os conhecimentos sobre as ervas e situações cotidianas, que foram mobilizados saberes de caráter experiencial de origem informal. Esse fato revela uma outra dimensão, o silêncio sobre as falas que viessem a associar a experiência do museu a processos formais.

Frente a esse silêncio, um fator que poderia ter sido discutido no artigo se refere à Formação dos professores. Coffani-Nunes et al. (2016) durante um curso de Formação Continuada com educadores do Ensino Fundamental, identificou que cerca de $23 \%$ dos professores participantes do curso eram formados em Biologia, consequentemente os demais não tiveram contato com a Botânica em suas graduações, sendo que a mesma parcela de professores declarou que sua Formação Inicial tinha sido insuficiente para contribuir em sua docência, esse fato pode ter alguma relação com os equívocos dos professores durante a experiência "Chá de Sentidos".

Nas conclusões da investigação de Faria, Jacobucci e Oliveira (2011), foi levantada a hipótese de que a dificuldade dos docentes em distinguir o espaço formal do não formal; estaria associada à pouca circulação de conhecimentos ligados à pesquisa em Educação. Provavelmente o foco dos autores se dirigiu para o relato da experiência, mas outros componentes menos ligados às concepções dos participantes, relativos à 
esfera profissional, como o tipo de Formação Inicial e a ausência de processos de Formação Continuada voltados para a Botânica, sejam parte fundamental dessa lacuna.

\section{7 - O processo de apropriação dos conceitos de Fotossíntese e Respiração}

\section{Celular por alunos em aulas de Biologia.}

Este trabalho teve como objetivo explorar a apropriação de conceitos sobre a Fotossíntese e Respiração Celular em alunos do Ensino Médio. As autoras Trazzi e Oliveira (2016b) utilizaram um experimento envolvendo a presença de uma planta em sistema aberto e fechado, levantamento de hipóteses, aplicação de uma prova e uma discussão sobre as respostas dos estudantes.

As características expostas acima, como autoria do trabalho, contexto de pesquisa, público alvo, o experimento e parte da metodologia são semelhantes aos do artigo analisado no ponto 3.1. Porém a mobilização dos referenciais teóricos e a natureza dos resultados se basearam em diferentes perspectivas.

Por meio das contribuições do teórico russo Mikhail Bakhtin sobre significação e apropriação de palavras, as autoras constataram que os estudantes balizaram suas respostas de acordo com a interpretação das palavras enunciadas pela professora, mas em alguns momentos atribuem significados diferentes. Nesse sentido, vinculam o conceito de absorção da água explicitado pela professora, ao significado da palavra alimentação.

O mesmo ocorre para a dificuldade dos alunos em associar o termo "alimento" com a nutrição da planta. Assim, as autoras discutem que o ato de "comer" não é vinculado à quebra da glicose e produção de energia, mas a um caráter utilitário de produção dessa molécula e sua ingestão por níveis superiores da cadeia alimentar.

Em outro momento, a Respiração Celular foi interpretada de maneira diversa pelos estudantes; como exemplo, destacamos a explicação correta realizada por uma menina que se norteou pelos agentes envolvidos no processo de Fotossíntese como a água e o gás carbônico, para depois incluí-los como referência na explicação da Respiração. Em outro caso, a Respiração Celular não foi articulada à Fotossíntese, permanecendo a ideia da degradação da glicose e produção de energia, suprimida pelo entendimento de que a planta produz seu alimento "se mantendo forte". 
A complexidade e ampla generalização dos conceitos de Fotossíntese e Respiração Celular, representou novamente uma dificuldade para o ensino. Trazzi e Oliveira (2016b) remetem que, por essas razões, os dois temas deveriam ser recorrentes no Ensino de Biologia, e a maneira de serem ensinados deveria ser pensada com antecedência pelos professores. Trazem também a noção de que as condições de produção, como provas descritivas, um excesso de termos e uma integração deficitária entre eles, geram grande dificuldade no entendimento cientificamente coerente de outros aspectos que estão ligados à Fotossíntese e Respiração Celular estudados em Botânica.

Os artigos analisados nesta seção trazem, em seus conteúdos diferentes abordagens sobre temas relevantes para o Ensino de Botânica. A revista Ciência \& Educação foi a única que não apresentou trabalhos nessa área no período que compreende os anos de 2010 a 2016. Para esse periódico, outro levantamento que cobriu os anos de 1998 a 2011 foi realizado por Bittencourt (2013) e obteve o mesmo resultado. O cenário encontrado significou que a ausência do Ensino de Botânica se estendeu por um período de dezoito anos, indicando a existência de um espaço ainda não explorado para a divulgação de publicações dessa área do conhecimento na revista.

\section{4- CONSIDERAÇÕES FINAIS}

A divulgação de pesquisas qualificadas em Ensino de Botânica possui uma expressão tímida em periódicos da área de Ensino de Ciências de referência. A quantidade de trabalhos que encontramos reflete tal realidade, e ainda que se considerassem os quatro artigos encontrados da revista IENCI um número satisfatório, os demais periódicos não sustentariam esse parâmetro, possuindo metade, nenhuma ou $1 / 4$ desse total de publicações.

Os temas tratados nas 7 investigações dos periódicos levantados se concentraram em três agrupamentos formulados em função das suas semelhanças temáticas: 1pesquisas relacionadas ao aprendizado sobre a Fotossíntese, 2- abordagens ligadas a espaços não formais e 3- trabalhos que analisam os conteúdos presentes no livro didático. 
Dentre os três agrupamentos, com o maior número de artigos, temos o das pesquisas sobre a formação de conceitos e significados relativos à Fotossíntese. Os autores mobilizaram nesses trabalhos referenciais teóricos ligados aos aspectos cognitivos de aprendizagem, utilizando o discurso dos estudantes durante momentos de atividades com experimentos e de aulas, além da utilização de interações dialógicas para compor seus materiais de análise. Os desafios principais nesse contexto temático foram a articulação dos conceitos de Fotossíntese com os da Respiração Celular pelos estudantes, o entendimento correto dos fenômenos e elementos envolvidos nesses processos e o desenvolvimento de um planejamento curricular adequado, de modo a apresentar esses temas de maneira integrada com os demais conteúdos de Botânica nas disciplinas escolares.

Em segundo lugar, temos o agrupamento de pesquisas com base no uso de espaços não formais. Nesses trabalhos, são pontuadas muitas dificuldades ligadas ao ensino da Botânica, dentre elas o desinteresse relacionado à falta da aproximação com as plantas e da percepção delas no cotidiano dos estudantes, além de um ensino carregado de terminologias e detalhes.

Um modo de superar essas condições consistiu na diversificação das metodologias e da rotina de aulas com a visita de espaços não formais. Os autores afirmaram que essa iniciativa em ambientes diferentes de ensino gerou uma aproximação que estimulou os estudantes a tocar nas plantas, observar melhor suas características físicas e vivenciar experimentos ao ar livre, possibilidades que despertaram o interesse e potencializaram as aulas de Botânica.

A abordagem sobre a análise dos conteúdos de Botânica em livros didáticos constituiu o terceiro agrupamento. Segundo Güllich (2011), este é um campo que carece de investigações pois há poucas ou nenhuma pesquisa na qual o currículo de Botânica é analisado com base no livro didático.

Os autores desse agrupamento identificaram aspectos curriculares em livros de diferentes épocas demonstrando como o Ensino de Ciências foi mudando ao longo do tempo e os reflexos desse processo nos conteúdos de Botânica. Constataram que houve uma melhora no livro mais próximo da atualidade pelo uso de recursos de imagem e gráficos, embora a linguagem escrita ainda tenha um caráter técnico. 
O livro didático interfere na ação docente, no currículo escolar e nos modos de ensino, devendo ser utilizado como um apoio e não origem do trabalho pedagógico. Dessa maneira, o tipo de investigação em questão contribui como referência para uma análise crítica em espaços de discussão escolar sobre a escolha do livro didático de Biologia (EMMEL; GÜLLICH; PANSERA-ARAÚJO, 2009).

Os artigos levantados trazem à tona discussões essenciais para um campo do Ensino de Ciências permeado de desafios como o da Botânica, mas há temas de ampla generalidade e relevância que também poderiam ser trabalhados, como os ciclos de vida e a reprodução vegetal.

Retomando a questão da quantidade de artigos, outros levantamentos corroboram o reconhecimento de uma divulgação científica pequena relativa ao Ensino de Botânica nas revistas. Em pesquisa realizada por Bittencourt (2013), outros periódicos de referência no Ensino de Ciências como a Revista Alexandria, Ciência em Tela e Revista de Ensino de Ciências e Matemática também apresentaram um baixo número de publicações.

As pesquisas selecionadas nesse estudo não representam avanços de amplo espectro para o Ensino de Botânica, mas constituem uma gama de contribuições específicas com base em problemas gerais já identificados por trabalhos anteriores. Tais esforços detalham e aprofundam contextos e possibilidades de trabalhar conteúdos, mesmo que, como já foi comentado, consistam em uma baixa quantidade de artigos.

Um caminho que pode ajudar na superação dessa baixa adesão ou produção em Botânica, consiste inicialmente no contínuo desenvolvimento de pesquisas que reflitam o estado do conhecimento da área; promovendo a identificação dos setores de produção onde há demandas, e indicando para a comunidade científica os âmbitos com maiores possibilidades de publicação, contribuição e aproveitamento de estudos já produzidos.

\section{5 - REFERÊNCIAS}

APPLE, M. W. Education, politics and social transformation. 2014. Disponível em <https://www.researchgate.net/publication/242261308_EDUCATION_POLITICS_AN D_SOCIAL_TRANSFORMATION>Acesso em: 25/06/2018. 
BACHELARD, G. A formação do espírito científico: Contribuições para uma psicanálise do conhecimento. $5^{\circ}$ reimpressão, Rio de Janeiro: Contraponto, 2007.

BITTENCOURT, I. M. A botânica no ensino médio: análise de uma proposta didática baseada na abordagem CTS. 2013. 152 f. Dissertação (Mestrado em Educação científica e Formação de professores) - Universidade Estadual do Sudoeste da Bahia, 2013.

COFFANI-NUNES et al. Formação continuada em botânica para professores do ensino fundamental da D.E. - Região Registro, SP. Revista da Associação Brasileira de Ensino de Biologia (SBEnBio), n. 9, p. 6934 - 6946, 2016.

DIAS, J.M.C; SCHWARZ, E. A; VIEIRA, E.R. A Botânica além da sala de aula. Currículos e saberes p. 149-160, Rio de Janeiro, 2000.

DIMOV, L. F.; PECHLIYE, M. M.; JESUS, R. C. Caracterização ontológica do conceito de fotossíntese e obstáculos epistemológicos e ontológicos relacionados com o ensino deste conceito. Investigações em ensino de ciências, Porto Alegre, v. 19, n.1, p. 7-28, 2014.

EMMEL, R.; GÜLLICH, R. I. C.; ARAÚJO, M. C. P. Interfaces da pesquisa sobre o livro didático de ciências. In: Encontro Nacional de Pesquisa em Educação em Ciências, 7., 2009, Florianópolis, Associação Brasileira de Pesquisa em Educação em Ciências. Anais... Santa Catarina: Florianópolis.

FARIA, R. L.; JACOBUCCI, D. F. C.; CARVALHO, D. F. Possibilidades de ensino de botânica em um espaço não-formal de educação na percepção de professoras de ciências. Ensaio: pesquisa em educação em ciências, Belo Horizonte, v.13, n.1, p.87104, 2011.

FERNANDES, R. C. A.; MEGID NETO, J. Pesquisas sobre o Estado da Arte em Educação em Ciências: uma revisão em periódicos científicos brasileiros. In: Encontro Nacional de Pesquisa em Educação em Ciências, 6., 2007, Florianópolis. Associação Brasileira de Pesquisa em Educação em Ciências. Anais... Belo Horizonte: ABRAPEC, 2007. p. 1-12.

GATT, S. et al. Young Maltese children's ideas about plants. Journal of biological education, United Kindgom, v. 41, n. 3, p. 117-122, 2007.

GIL-PÉREZ, D.; MONTORO, I. F.; ALÍS, J. C.; CACHAPUZ, A.; PRAIA, J. Por uma imagem não deformada do trabalho científico. Ciência \& Educação, Bauru, v.7, n.2, p.125-153, 2001.

GOHN, M. G. Educação não formal, participação da sociedade civil e estruturas colegiadas nas escolas. Revista Ensaio: Avaliação de Políticas Públicas em Educação, Rio de Janeiro, v. 14, n. 50, p. 11-25, 2006.

GÜLLICH, R. I. C.; O livro didático e o ensino de Ciências. Palestra proferida no ano de 2011.

GÜLLICH, R. I. C.; SILVA, L. H. A. O Enredo da Experimentação no Livro Didático: construção de conhecimentos ou reprodução de teorias e verdades científicas? Ensaio: Pesquisa em educação em ciências, Belo Horizonte, v. 15, n.2, p. 155-167, 2013. 
LEME, J. S.; URSI, S. Ciclos de Vida das Plantas: uma visão integradora. Revista da Associação Brasileira de Ensino de Biologia (SBEnBio), v. 7, p.4288-4297, 2014.

LEOPOLDO, D. L. Proposições para a reflexão sobre a formação continuada de professores em Ensino de Botânica. 2018. 211 f. Dissertação (Mestrado em Educação para a Ciência) - Universidade Estadual Paulista "Júlio de Mesquita Filho", Faculdade de Ciências, Bauru, São Paulo, 2018.

MARINHO, L. C.; SETÚVAL, F. A. R.; AZEVEDO, C. O. Botânica geral de angiospermas no ensino médio: uma análise comparativa entre livros didáticos. Investigações em ensino de ciências, Porto Alegre, v. 20, n. 3, p. 237-258, 2015.

MAYR, E. The Autonomy of Biology. Ludus Vitalis, v. 7, n. 28, p. 15-27, 2004.

RAHM, J. "Eu sempre gostei de tocar o solo e plantar coisas! " Uma análise especial da jardinagem juvenil em um jardim botânico. Revista brasileira de pesquisa em educação em ciências (RBPEC), v. 14, n.2, p. 137-145, 2014.

RAZERA, J. C. C. Contribuições da Cienciometria para a área brasileira de Educação em Ciências. Ciênc. Educ., Bauru, v. 22, n. 3, p. 557-560, 2016.

ROMANOWSKI, J. P.; ENS, R. T. As pesquisas denominadas do tipo Estado da Arte em educação. Diálogo educacional, Curitiba, v. 6, n.19, p. 37-50, 2006.

SALATINO, A.; BUCKERIDGE, M. Mas de que te serve saber Botânica? Estudos Avançados, v. 30, n. 87, p. 177-196, 2016.

SCHNEEKLOTH, L. H. Play environments for visually impaired children. Journal of Visual Impairment \& Blindness, v.4, n. 83, p.196-201, 1989.

SILVA, J. N.; GHILARDI-LOPES, N. P. Botânica no Ensino Fundamental: diagnósticos de dificuldades no ensino e da percepção e representação da biodiversidade vegetal por estudantes. Revista Electrónica de Enseñanza de las Ciencias, v. 13, n. 2, p. 115-135, 2014.

SILVA, J. R. S.; SANO, P. T. O ensino de botânica na visão dos estudantes de Ciências biológicas. In: Congreso Iberoamericano de Investigación en Enseñanza de las Ciências, 1., 2011, Campinas, ABRAPEC. Anais... São Paulo: Campinas, p. 1-9.

SILVA, L. M.; CAVALLET, V. J.; ALQUINI, Y. O professor, o aluno e o conteúdo de botânica. Educação, Santa Maria, v. 31, n. 1, p. 67-80, 2006.

SIMMONS, D. A. Urban children's preferences for Nature: Lessons for Environmental education. Children's Environment, v. 11, n. 3, p. 194-203, 1994.

TOWATA, N.; URSI, S.; SANTOS, D. Y. A. C. Análise da Percepção de Licenciandos sobre o "Ensino de Botânica na Educação Básica". Revista da Associação Brasileira de Ensino de Biologia (SBEnBio), São Paulo, n. 3, 2010.

TRAZZI, P. S. S.; OLIVEIRA, I. M. A ação mediada no processo de formação dos conceitos científicos de fotossíntese e respiração celular em aulas de biologia. Investigações em ensino de ciências, Porto Alegre, v.21, n. 2, p. 121-136, 2016 a. 
TRAZZI, P. S. S.; OLIVEIRA, I. M. O processo de apropriação dos conceitos de fotossíntese e respiração celular por alunos em aulas de biologia. Ensaio: pesquisa em educação em ciências, v. 18, n.1, p. 85-106, 2016 b.

TUNNICLIFFE, S. D.; REISS, M. J. Building a Model of the Environment: How do Children See Plants? Journal of Biological Education, v. 34, n. 4, p. 172- 177, 2000.

ZOMPERO, A. F.; LABURU, C. E. Significados de fotossíntese apropriados por alunos do ensino fundamental a partir de uma atividade investigativa mediada por multimodos de representação. Investigações em ensino de ciências, Porto Alegre, v. 16, n. 2, p. 179-199, 2011. 